\title{
Concentrations of canine prostate specific esterase, CPSE, at baseline are associated with the relative size of the prostate at three-year follow-up
}

Bodil S. Holst ${ }^{1 *}$ D, Sofia Carlin', Virginie Fouriez-Lablée ${ }^{2}$, Sofia Hanås ${ }^{1,3}$, Sofie Ödling ${ }^{3}$, Liss-Marie Langborg ${ }^{4}$, S. J. Kumari A. Ubhayasekera ${ }^{5}$, Jonas Bergquist ${ }^{5}$, Jesper Rydén ${ }^{6}$, Elin Holmroos ${ }^{1}$ and Kerstin Hansson ${ }^{1}$

\begin{abstract}
Background: Enlargement of the prostate is associated with prostatic diseases in dogs, and an estimation of prostatic size is a central part in the diagnostic workup. Ultrasonography is often the method of choice, but biomarkers constitute an alternative. Canine prostate specific esterase (CPSE) shares many characteristics with human prostate specific antigen (PSA) and is related to prostate size. In men with clinical symptoms of prostatic disease, PSA concentrations are related to prostate growth. The aims of the present follow-up study were to evaluate if the concentration of CPSE is associated with future growth of the prostate, and if analysis of a panel of 16 steroids gives further information on prostatic growth. Owners of dogs included in a previous study were 3 years later contacted for a follow-up study that included an interview and a clinical examination. The prostate was examined by ultrasonography. Serum concentrations of CPSE were measured, as was a panel of steroids.
\end{abstract}

Results: Of the 79 dogs included at baseline, owners of 77 dogs (97\%) were reached for an interview, and 22 were available for a follow-up examination. Six of the 79 dogs had clinical signs of prostatic disease at baseline, and eight of the remaining 73 dogs (11\%) developed clinical signs between baseline and follow-up, information was lacking for two dogs. Development of clinical signs was significantly more common in dogs with a relative prostate size of $\geq 2.5$ at baseline $(n=20)$ than in dogs with smaller prostates $(n=51)$. Serum concentrations of CPSE at baseline were not associated with the change in prostatic size between baseline and follow-up. Serum concentrations of CPSE at baseline and at follow-up were positively associated with the relative prostatic size $\left(S_{\text {rel }}\right)$ at follow-up. Concentrations of corticosterone $(P=0.024)$, and the class corticosteroids $(P=0.0035)$ were positively associated with the difference in $S_{\text {rel }}$ between baseline and follow-up.

Conclusions: The results support the use of CPSE for estimating present and future prostatic size in dogs $\geq 4$ years, and the clinical usefulness of prostatic size for predicting development of clinical signs of prostatic disease in the dog. The association between corticosteroids and prostate growth warrants further investigation.

Keywords: Dog, Steroids, Corticosteroids, Prostate hyperplasia, Biomarker, Ultrasound

\footnotetext{
* Correspondence: Bodil.Strom-Holst@slu.se

'Department of Clinical Sciences, Swedish University of Agricultural Sciences, Box 7054, SE-750 07 Uppsala, Sweden

Full list of author information is available at the end of the article
}

(c) The Author(s). 2021 Open Access This article is licensed under a Creative Commons Attribution 4.0 International License, which permits use, sharing, adaptation, distribution and reproduction in any medium or format, as long as you give appropriate credit to the original author(s) and the source, provide a link to the Creative Commons licence, and indicate if changes were made. The images or other third party material in this article are included in the article's Creative Commons licence, unless indicated otherwise in a credit line to the material. If material is not included in the article's Creative Commons licence and your intended use is not permitted by statutory regulation or exceeds the permitted use, you will need to obtain permission directly from the copyright holder. To view a copy of this licence, visit http://creativecommons.org/licenses/by/4.0/. The Creative Commons Public Domain Dedication waiver (http://creativecommons.org/publicdomain/zero/1.0/) applies to the data made available in this article, unless otherwise stated in a credit line to the data. 


\section{Background}

The prostate is an androgen-dependent gland. In intact middle-aged and old dogs, an enlarged prostate is a natural sequel to androgen production, and with age almost all will develop benign prostatic hyperplasia (BPH) [1$3]$. The type of hyperplasia varies with age, from a glandular hyperplasia in younger dogs to a complex form with glandular hyperplasia, increased amount of stroma, often cystic alveoli and chronic inflammation in older dogs $[1,2]$. The prostate growth is more pronounced during the first 4 years and then reaches a plateau [2]. After 4 years, a correlation between the size and age is not always evident [4], and in senior dogs, an involution may occur [5]. Although growth is androgen dependent, it is not related to increasing testosterone concentrations. Instead, a mild decrease in serum testosterone concentrations is seen with increasing age, while concentrations of estrogens remain similar or increase [3, 6]. As a consequence, the testosterone/estradiol relationship has been described as a measurable indicator of $\mathrm{BPH}$ [7]. In men, both estrogen receptor (ER) $\alpha$ and $\beta$ have been described to be more strongly expressed in epithelial cells of hyperplastic than of normal prostates [8]. Beside a decreased androgen/estrogen ratio, several other factors, including stromal growth factors and chronic inflammation, have been indicated to play a role in the pathogenesis of BPH [9].

Although most, if not all, intact males will develop $\mathrm{BPH}$ with time, only a sub-population will show related clinical signs, often associated with a prostate that is markedly increased in size [10]. Signs related to BPH include ribbon-like stools [11], hematuria, incontinence and tenesmus [12]. The sperm quality may be affected leading to fertility problems [13]. Clinical signs may be insidious in nature, and, at least initially, go unnoticed by owners [4]. The fact that many male dogs have subtle signs of $\mathrm{BPH}$, and veterinary care may not be sought until the signs have become severe, makes $\mathrm{BPH}$ a potential welfare problem in the ageing male. In addition, presence of $\mathrm{BPH}$ increases the risk of developing other prostate diseases, mainly prostatitis, a condition that may be life-threatening [12].

Because $\mathrm{BPH}$ and most other prostatic diseases are associated with an enlargement of the prostate, estimation of prostatic size is a central part in the diagnostic workup. Rectal palpation is a quick and easy first step [14], although not always feasible in larger dogs, or in older dogs, as the position of the prostate often changes with age from the pelvic to the abdominal cavity, and ultrasonography is often the method of choice $[15,16]$. An ultrasound examination not only gives information on size, but also on shape, contour, echogenicity and symmetry, and it also adds information on adjacent soft tissue [17]. The drawback is related to availability of equipment and skill of the veterinarian performing the investigation. An alternative for estimating an increased prostatic size is analysis of serum concentration of the biomarker canine prostate specific esterase (CPSE) [4]. CPSE is an arginine esterase, and the major secretory product of the canine prostate [18]. Serum CPSE concentrations are significantly higher in dogs with $\mathrm{BPH}$ than in normal dogs $[7,19,20]$. Several authors have suggested inclusion of CPSE analysis in the diagnostic workup of dogs with clinical signs of $\mathrm{BPH}$, and for screening of geriatric dogs $[4,21,22]$. There are several similarities between CPSE in dogs and prostate specific antigen (PSA) in men. Both are serine proteases with similar regulation $[18,23]$. In men, it has been described that the concentrations of PSA may predict the future growth of the prostate gland [24]. If this would be the case also for CPSE in dogs, the diagnostic value of a CPSE analysis would increase further.

The aims of the present follow-up study were to evaluate if the concentration of CPSE is associated with future growth of the prostate, and if analysis of a panel of 16 steroids gives further information on prostatic growth.

\section{Results}

The number of dogs included in the different parts of the study is summarized in Fig. 1.

\section{Interview}

Of 79 dogs included at baseline, six dogs had clinical signs of prostatic disease and 73 dogs had no such clinical signs. Contact was established with owners of 77 dogs (97\%). The interviews revealed that in addition to the six dogs with clinical signs at inclusion, eight dogs $(8 / 73,11 \%)$ had developed clinical signs of prostatic disease since baseline, the most common being haematuria, urinary incontinence and tenesmus. The median baseline concentration of CPSE for dogs that later developed clinical signs was $135 \mathrm{ng} / \mathrm{ml}$ (interquartile range, IQR 71-402 $\mathrm{ng} / \mathrm{ml}$ ), and for dogs that did not develop clinical signs $61 \mathrm{ng} / \mathrm{ml}$ (IQR $<25$ to $130 \mathrm{ng} / \mathrm{ml}$ ). The difference between these groups was not significant $(P=$ $0.1)$. Dogs with a $S_{\text {rel }}$ of $\geq 2.5$ at baseline $(n=20)$ had significantly more often than those with a smaller $S_{\text {rel }}$ $(n=51)$ developed clinical signs of prostatic disease $(P=$ 0.035). Information from two dogs was lacking. Median (IQR) $S_{\text {rel }}$ at baseline was $3.0(1.7-3.5)$ for dogs that had developed clinical signs and $1.8(1.3-2.4)$ for dogs that had not developed clinical signs.

Of the 79 dogs that were included at baseline, 22 (28\%) were available for a follow-up examination. Reasons for not participating in the follow-up were for the other 57 dogs euthanasia $(n=25)$, surgical castration $(n=8)$, treatment with osaterone acetate $(n=7)$, long distance $(n=7)$, treatment with deslorelin $(n=6)$, no 


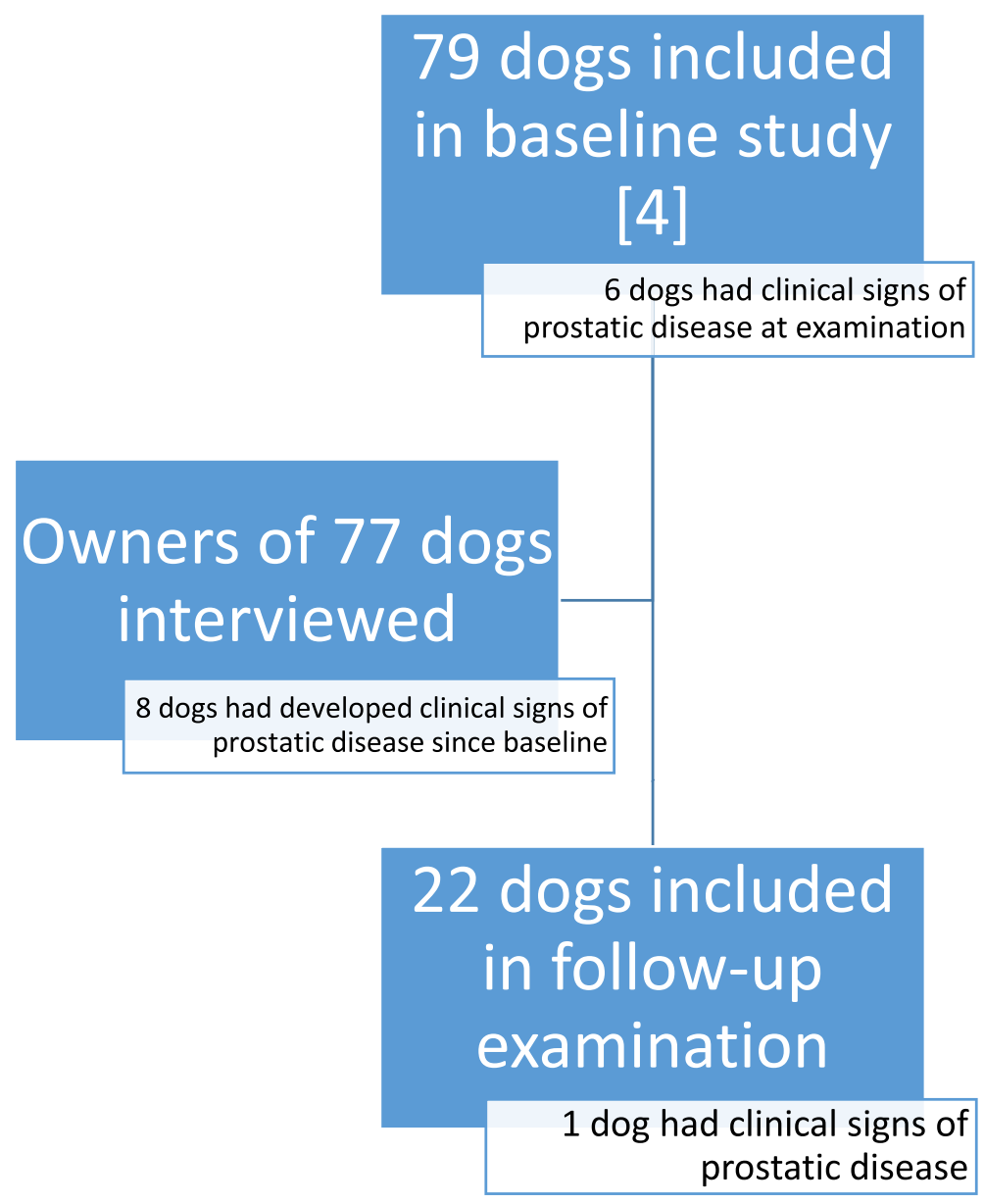

Fig. 1 Chart of the study design with number of dogs included in the different steps

answer $(n=2)$, treatment with both osaterone acetate and deslorelin $(n=1)$, or was not interested in participating $(n=1)$. The most common causes for euthanasia were neoplasia $(n=11)$, multifactorial $(n=5)$, age $(n=4)$, and joint problems $(n=4)$.

\section{Ultrasonography, CPSE and steroid concentration}

Of the 22 dogs available for follow-up, 21 did not have signs of prostatic disease. One Rottweiler had a sanguineous urethral discharge that was evident when in contact with bitches in heat. The $S_{\text {rel }}$ of his prostate was 2.9, and had not changed significantly since baseline. He had $>5$ intra-prostatic cysts at follow-up.

The 22 dogs were of 14 different breeds. Their median age and weight at baseline were 5.2 years (IQR 4.0-7.0) and $27.8 \mathrm{~kg}$ (IQR 12.5-37.5), respectively. At follow-up, their median age was 8.8 years (IQR 7-10.3) and median weight was $26.3 \mathrm{~kg}$ (IQR 13.8-37.7). At baseline, $27 \%$ of these 22 dogs had prostates with a relative size $\geq 2.5$, and at follow-up this proportion was $41 \%$.

The $\mathrm{V}$ and $\mathrm{S}_{\text {rel }}$ had increased slightly but significantly from baseline to follow-up $(P=0.006$, Table 1$)$. The volume had increased in 12 dogs (median age 9.5 years (IQR 8.0-11.8), median CPSE concentration at baseline $59.1 \mathrm{ng} / \mathrm{ml}$ (IQR 15.4-111.0)). For nine dogs, volume had changed less than 15\%. Their median age was 7 years (IQR 7.0-8.8), median CPSE concentration at baseline $47 \mathrm{ng} / \mathrm{ml}$ (28.1-77.0). The volume of the prostate had decreased $27 \%$ in one 13-year-old dog with CPSE at baseline $95 \mathrm{ng} / \mathrm{ml}$. The change in $S_{\text {rel }}$ between baseline and follow-up in individual dogs is shown in Fig. 2.

Using multiple regression, baseline CPSE concentrations and concentrations at follow-up were significantly

Table 1 Serum concentration of CPSE, size of the prostate, and dogs with presence of cysts at baseline and follow-up $(n=22)$

\begin{tabular}{lllll}
\hline Parameter & & Baseline & Follow-up & $P$-value \\
\hline CPSE, ng/ml & Median (IQR) & $52(24-97)$ & $107(49-416)$ & 0.001 \\
$\mathrm{~V}_{1} \mathrm{~cm}^{3}$ & Median (IQR) & $18(12-30)$ & $21(15-38)$ & 0.006 \\
$\mathrm{~S}_{\text {rel }}$ & Median (IQR) & $1.8(1.2-2.2)$ & $2.2(1.4-2.9)$ & 0.006 \\
Cysts, presence & $\mathrm{N}(\%)$ & $12(54)$ & $18(82)$ & 0.18
\end{tabular}

CPSE canine prostate specific esterase, $V$ Volume of the prostate, $S_{\text {rel }}$ relative size of the prostate, Cysts prostatic cysts 


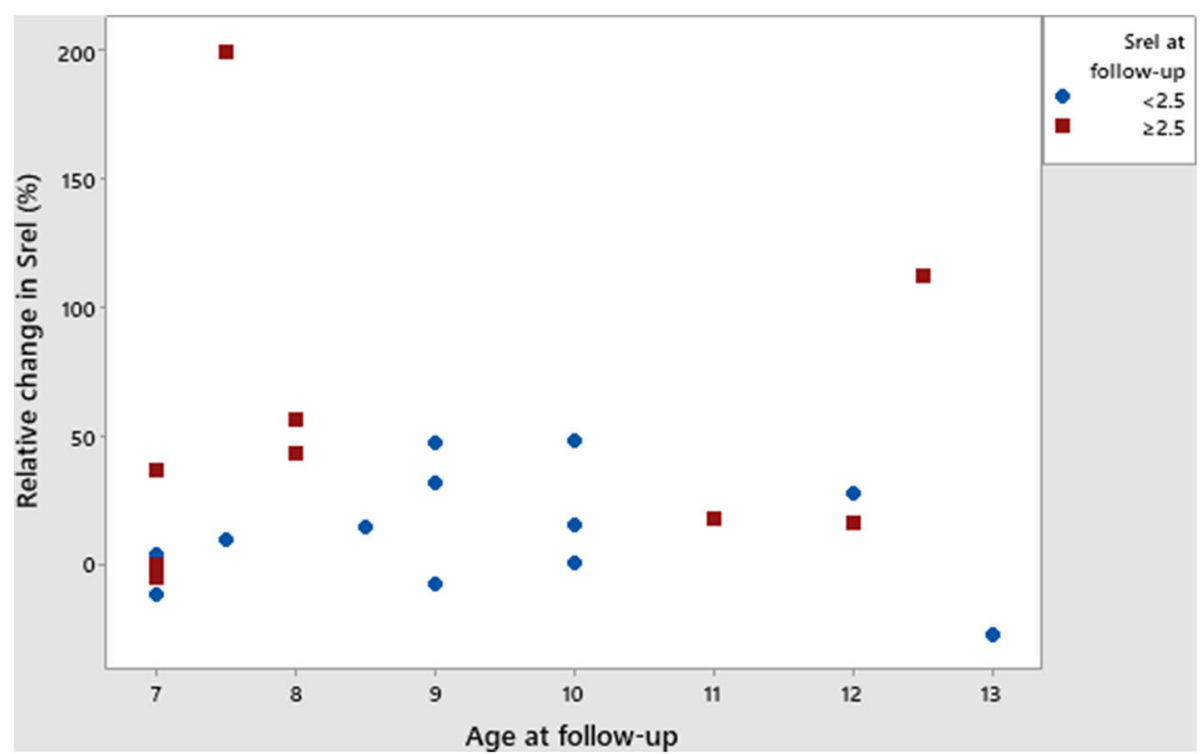

Fig. 2 Change in relative size, $S_{\text {rel, }}$ of the prostate between baseline and follow-up, in dogs $(n=22)$ of various ages

associated with $\mathrm{S}_{\text {rel }}$ at follow-up (Table 2). The Pearson correlation coefficient $(r)$ between baseline CPSE and Srel at follow up was $0.53(P=0.011)$. Age and weight were not significantly associated with $S_{\text {rel }}$ at follow-up. None of the steroids, analyzed separately, as classes or as ratios, were significantly associated with the $S_{\text {rel }}$ at follow-up. One steroid, corticosterone was associated with the difference in $S_{\text {rel }}$ between baseline and followup (regression coefficient 0.5 , adjusted $R^{2}=0.75, P=$ 0.024 ), as was the class corticosteroids (regression coefficient 0.008 , adjusted $R^{2}=0.34, P=0.003$ ). Median concentrations of steroids in dogs with different $S_{\text {rel }}$ are presented in Table 3.

The shape of the prostate was symmetrical both at baseline and at follow-up in 17 dogs. It changed from asymmetrical to symmetrical in two dogs and from symmetrical to asymmetrical in three dogs. The contour remained smooth in all dogs. The parenchyma did not change for 17 dogs; seven with a homogenous and 10 with heterogeneous echogenicity. It changed to heterogeneous in four dogs and to homogeneous in one dog. At baseline, 12 dogs (54\%) had prostatic cysts, all with one to five cysts. At follow-up, 18 dogs (82\%) had detectable cysts: five had one to five cysts as previously, and five had an increased number of cysts (>5) compared to baseline. Of 10 dogs that did not have any cysts at baseline, eight had developed one to five cysts at follow-up.

\section{Discussion}

Circulating biomarkers for the evaluation of the canine prostate are valuable for the practicing veterinarian with limited access to an ultrasound equipment. Concentrations of CPSE are related to the size of the prostate [4] and to the presence of $\mathrm{BPH}[7,19,20]$. The analysis of CPSE can therefore contribute with important information both in the workup of cases with clinical signs related to the prostate, and in the screening panel for old male dogs. The samples must be taken after a proper sexual rest, as ejaculation increases the CPSE concentration in serum [25]. We have previously described that clinical signs were more common in dogs with a $S_{\text {rel }}$ of $\geq 2.5$, with a CPSE concentration of $\geq 90 \mathrm{ng} / \mathrm{ml}$ [4]. In the present study, dogs with a baseline $S_{\text {rel }} \geq 2.5$ significantly more often had developed clinical signs of prostatic disease at follow-up than those with smaller $S_{\text {rel }}$. This supports the clinical usefulness of this cut-off. The concentrations of CPSE did not differ between dogs that had developed clinical signs and those that had not done so. We have previously described an association between CPSE concentrations and size of the prostate [4], and the lack of association between CPSE concentrations

Table 2 Association between CPSE concentration at baseline and follow-up, and relative prostatic size at follow-up, adjusted $R^{2}=0.51$

\begin{tabular}{lllll}
\hline Parameter & Regression coefficient & Standard Error & t-value & $P$-value \\
\hline CPSE baseline & 0.005 & 0.0016 & 3.3 & 0.004 \\
CPSE follow-up & 0.003 & 0.00079 & 3.5 & 0.003 \\
\hline
\end{tabular}

CPSE canine prostate specific esterase 
Table 3 Concentration of the different steroids, classes of steroids, ratios of classes of steroids and of canine prostate specific esterase (CPSE) in dogs at follow-up

\begin{tabular}{|c|c|c|c|c|}
\hline Steroid & Prostatic size & $\mathrm{N}$ & Median (ng/ml) & IQR \\
\hline \multirow[t]{2}{*}{ Aldosterone } & $<2.5$ & 13 & 0.10 & $0.04-0.31$ \\
\hline & $\geq 2.5$ & 9 & 0.26 & $0.17-0.44$ \\
\hline \multirow[t]{2}{*}{ Androsterone } & $<2.5$ & 13 & 0.069 & $0.04-0.16$ \\
\hline & $\geq 2.5$ & 9 & 0.041 & $0.01-0.15$ \\
\hline \multirow[t]{2}{*}{ Androstenedione } & $<2.5$ & 13 & 1.43 & $0.4-2.16$ \\
\hline & $\geq 2.5$ & 9 & 2.20 & $1.2-3.4$ \\
\hline \multirow[t]{2}{*}{ Cortisol } & $<2.5$ & 13 & 36.7 & $17.3-58.6$ \\
\hline & $\geq 2.5$ & 9 & 21.5 & $14.5-38.9$ \\
\hline \multirow[t]{2}{*}{ Cortisone } & $<2.5$ & 13 & 14.75 & $10.4-20.32$ \\
\hline & $\geq 2.5$ & 9 & 10.41 & $7.5-23.60$ \\
\hline \multirow[t]{2}{*}{ Corticosterone } & $<2.5$ & 13 & 1.81 & $1.2-3.77$ \\
\hline & $\geq 2.5$ & 9 & 1.38 & $0.7-2.61$ \\
\hline \multirow[t]{2}{*}{ 11-Deoxycorticosterone } & $<2.5$ & 13 & 0.40 & $0.13-0.79$ \\
\hline & $\geq 2.5$ & 9 & 0.17 & $0.076-0.31$ \\
\hline \multirow[t]{2}{*}{ 11-Deoxycortisol } & $<2.5$ & 13 & 6.82 & $4.2-8.39$ \\
\hline & $\geq 2.5$ & 9 & 4.86 & $1.96-8.29$ \\
\hline \multirow[t]{2}{*}{ DHEA } & $<2.5$ & 13 & 0.63 & $0.34-2.53$ \\
\hline & $\geq 2.5$ & 9 & 1.56 & $0.58-2.32$ \\
\hline \multirow[t]{2}{*}{ Etiocholanolone } & $<2.5$ & 13 & 0.24 & $0.18-0.32$ \\
\hline & $\geq 2.5$ & 9 & 0.34 & $0.29-0.44$ \\
\hline \multirow[t]{2}{*}{ 17a-hydroxyprogesterone } & $<2.5$ & 13 & 0.11 & $0.079-0.22$ \\
\hline & $\geq 2.5$ & 9 & 0.14 & $0.070-0.21$ \\
\hline \multirow[t]{2}{*}{ Pregnanolone } & $<2.5$ & 13 & 0.46 & $0.34-0.60$ \\
\hline & $\geq 2.5$ & 9 & 0.46 & $0.39-0.54$ \\
\hline \multirow[t]{2}{*}{ Progesterone } & $<2.5$ & 13 & 0.14 & $0.078-0.29$ \\
\hline & $\geq 2.5$ & 9 & 0.14 & $0.065-0.22$ \\
\hline \multirow[t]{2}{*}{ Testosterone } & $<2.5$ & 13 & 1.40 & $0.98-3.30$ \\
\hline & $\geq 2.5$ & 9 & 2.41 & $2.17-4.59$ \\
\hline \multirow[t]{2}{*}{ Estrone } & $<2.5$ & 13 & 0.023 & $0.0004-0.05$ \\
\hline & $\geq 2.5$ & 9 & 0.036 & $0.013-0.059$ \\
\hline \multirow[t]{2}{*}{ Estradiol } & $<2.5$ & 13 & 0.0072 & $0.00-0.017$ \\
\hline & $\geq 2.5$ & 9 & 0.0075 & $0.00-0.016$ \\
\hline \multirow[t]{2}{*}{ CPSE (follow-up) } & $<2.5$ & 13 & 83.0 & $29.6-118.4$ \\
\hline & $\geq 2.5$ & 9 & 153.3 & $91.8-550.2$ \\
\hline \multirow[t]{2}{*}{ SUM estrogens } & $<2.5$ & 13 & 0.039 & $0.0069-0.059$ \\
\hline & $\geq 2.5$ & 9 & 0.036 & $0.021-0.078$ \\
\hline \multirow[t]{2}{*}{ SUM androgens } & $<2.5$ & 13 & 3.45 & $2.11-8.5$ \\
\hline & $\geq 2.5$ & 9 & 9.13 & $4.45-11.6$ \\
\hline \multirow[t]{2}{*}{ SUM corticosteroids } & $<2.5$ & 13 & 57.43 & $43.36-91.21$ \\
\hline & $\geq 2.5$ & 9 & 39.6 & $28.3-71.0$ \\
\hline \multirow[t]{2}{*}{ SUM progestins } & $<2.5$ & 13 & 0.79 & $0.602-1.01$ \\
\hline & $\geq 2.5$ & 9 & 0.69 & $0.625-1.074$ \\
\hline Androgens/estrogens & $<2.5$ & 11 & 140 & $87-301$ \\
\hline
\end{tabular}


Table 3 Concentration of the different steroids, classes of steroids, ratios of classes of steroids and of canine prostate specific esterase (CPSE) in dogs at follow-up (Continued)

\begin{tabular}{lllll}
\hline Steroid & Prostatic size & N & Median $(\mathbf{n g} / \mathbf{m l})$ & IQR \\
\hline & $\geq 2.5$ & 9 & 202.5 & $96.2-481.9$ \\
Progestins/estrogens & $<2.5$ & 11 & 23.4 & $11.6-31.6$ \\
& $\geq 2.5$ & 9 & 23.05 & $9.64-30.66$ \\
Corticosteroids/estrogens & $<2.5$ & 11 & 1838 & $619-3710$ \\
Androgens/progestins & $\geq 2.5$ & 9 & 1127 & $392-5148$ \\
& $<2.5$ & 13 & 5.44 & $2.5-11.27$ \\
Corticosteroids/androgens & $\geq 2.5$ & 9 & 8.34 & $7.27-16.47$ \\
& $<2.5$ & 13 & 19.18 & $6.44-28.19$ \\
Corticosteroids/progestins & $\geq 2.5$ & 9 & 5.66 & $3.33-10.50$ \\
& $<2.5$ & 13 & 84.6 & $44.6-104.5$ \\
\hline
\end{tabular}

and development of clinical signs in the present study may be due to the relatively small study population, with eight of 73 dogs developing clinical signs.

Concentrations of PSA in men with moderate to severe clinical signs and an enlarged prostate have been described to predict prostate growth [24]. The PSA analysis thus contributes with specific information in this group of patients. In the present study, CPSE concentrations at baseline were significantly correlated with $S_{\text {rel }}$ at follow up. The concentration of CPSE is thus not only correlated with present prostatic size, but also with the future size. However, although CPSE is similar to PSA, there was no association between baseline CPSE concentrations and the difference in $S_{\text {rel }}$ between baseline and follow-up. The study population of dogs differed from the study in men in that most dogs were without clinical signs, and not all had enlarged prostates. It may therefore be that an association between CPSE and difference in $S_{\text {rel }}$ would have been detected with a different study population, including only dogs with enlarged prostates and clinical signs, or with a larger study population.

In the present study, $11 \%$ of the dogs from the baseline study with owners that were interviewed had, according to their owners, developed clinical signs of prostatic disease during the 3-year-period after the examination at baseline. These results highlight that clinical signs related to the prostate are common in intact male dogs > 4 years. When included in the study at baseline, these dog owners became aware of prostatic diseases, and this awareness, together with the fact that all dogs were $>4$ years old, may have contributed to this relatively high proportion of dogs with clinical signs.

In a previous study on dogs registered in a teaching veterinary hospital database, $0.7 \%$ had prostatic disorders [26]. This much lower number is likely influenced by the age distribution. It has previously been described that a large proportion of visits to an animal hospital consists of young dogs [27]. Another contributing factor is likely a proportion of castrated dogs, and another breed distribution, as the prevalence of prostatic disease differs between different breeds and sizes of dogs [26]. Clinical signs of prostatic disease may be insidious and may not lead to a visit at a veterinarian [4]. A low awareness of prostatic disease among general dog owners indicates that dogs getting veterinary care for this condition are only the tip of an iceberg. Due to this, many male dogs may suffer unnecessarily from a curable condition. Prevention screening of the prostate of male dogs has been recommended $[4,28]$, and is supported by the present study. The present results also point to the education of dog owners on the clinical signs of prostate disease, and possibilities for treatment, as a means to increase health and welfare of male dogs.

Despite the relationship between $\mathrm{BPH}$ and size of the prostate, and between prostate size and clinical signs, it should be noted that although $41 \%$ of the dogs at follow-up had $S_{\text {rel }}>2.5$, only one of them (4\%) had clinical signs of prostatic disease. In men, prostate size correlates poorly with clinical signs [29], indicating that other factors contribute. One such factor is prostatic fibrosis that is related to clinical signs in men [30]. Collagen structure in prostates of dogs and men is similar [31]. The majority of collagen is localized to the prostatic urethra, and a dense collagen network is present in capsular regions. Older, intact dogs have denser collagen fibers and thicker capsular fibers than young, intact males [31]. The presence of urinary signs in male dogs may thus be related to fibrosis, as in men. In men, the prostate has different zones, with $\mathrm{BPH}$ occurring more commonly in the transitional zone, surrounding the urethra [32], which is one reason for signs not being directly related to the overall size of the prostate. The canine prostate does not have different zones, and glandular proliferation occurs in all portions of the gland [1, 
15]. However, more nodular changes may be present, and cysts more common, in the periurethral area [1]. In older dogs, when the hyperplasia commonly is of the complex type, the presence of cysts in this area may be related to blood-tinged discharges.

During the 3 years between baseline and follow-up, $S_{\text {rel }}$ of the prostate had increased significantly. This is in accordance with previous studies showing that the prostate gland increases in size with age in intact males $[1,2]$. However, the median increase was rather low. The same pattern was not seen in all dogs, and in $45 \%$ of the dogs, the prostate had remained similar in size, or even decreased. The decrease in $S_{\text {rel }}$ in one dog may be caused by senile involution [5] and the proportion with similar $S_{\text {rel }}$ likely represents the plateau after 4 years, described previously [2]. Not only the $S_{\text {rel }}$ increased between baseline and follow-up, so did the proportion of dogs with cysts, although not significantly. At baseline all dogs with cysts had only few cysts, but at follow-up five of the 18 dogs with cysts had more than five cysts. The shape of the prostate was symmetrical both at baseline and at follow-up in $77 \%$ of the dogs. The presence of prostatic cysts is typical for the complex form of $\mathrm{BPH}$, dominating from 7 years of age in beagles [1].

The pathogenesis behind BPH is complex, and modifiable as well as non-modifiable risk factors are suggested in men, including inflammation, growth factors and endocrine factors $[9,33]$. A role for steroids in the development of BPH has been indicated since long. Acinar basal cells in the canine prostate are the major proliferative cell type, and express the androgen receptor [34], and $\mathrm{BPH}$ is an androgen-dependent condition. However, although the prevalence of $\mathrm{BPH}$ increases with age, testosterone concentrations tend to decrease [3]. In the present study, we used SFC-MS/MS to evaluate the concentration of 16 steroids in relation to the size of the prostate. The advantage with this method is the possibility to identify and quantify a large number of steroids within a short time using a small sample volume. Panels of steroids, and ratios between them, have been described to potentially have advantages in personalized medicine for men with prostatic cancer [35]. In the present study, no single steroid, class of steroids or ratio between different classes were associated with $S_{\text {rel }}$ at follow-up. The disadvantage of this study is the relatively low number of dogs included in this analysis, leading to reduced power, which may be one explanation for this lack of significant associations. Corticosterone and the class corticosteroids were positively associated with the difference in $S_{\text {rel }}$ between baseline and follow-up. The association between the difference in $\mathrm{S}_{\text {rel }}$ and corticoids is interesting. Chronic stress activates the hypothalamicpituitary-adrenal axis, leading to increased concentrations of corticosteroids and inflammatory responses, and inflammation has been suggested as a contributing factor to $\mathrm{BPH}$ [33]. However, corticosterone is not a primary corticosteroid in dogs, and the results should therefore be interpreted with caution. Further studies are required before any conclusions can be drawn on the relationship between stress and $\mathrm{BPH}$ in dogs.

Although owners of $97 \%$ of the dogs that were included at baseline were reached for interviews, only $28 \%$ of the dogs were available for a clinical follow-up. A general problem with follow-up studies of conditions affecting middle-aged or older dogs is that a proportion of them will be euthanized or treated so that they have to be excluded. In the present study, 32\% had been euthanized, many from tumours or joint disease, previously described common causes of mortality [36]. Twentyeight per cent of the dogs included at baseline were excluded because of the exclusion criteria; surgical or medical castration, or treatment for prostatic disease. Only one dog owner expressed no interest in participating in the clinical follow-up. The included dogs can therefore be considered representative for intact male dogs that have not been treated for prostatic disease.

\section{Conclusion}

CPSE concentrations at baseline and follow-up are significantly associated with $S_{\text {rel }}$ at follow-up but not with the difference in $S_{\text {rel }}$ between baseline and follow-up. Corticosteroids, and specifically corticosterone, were associated with the difference in $S_{\text {rel }}$ between baseline and follow-up. Dogs with a baseline $S_{\text {rel }} \geq 2.5$ were significantly more likely to develop clinical signs of prostatic disease than other dogs. Clinical signs had developed in $11 \%$ of dogs $>4$ years old during the three-year followup period.

\section{Methods \\ Study design}

Owners to dogs included in a previous study [4] were contacted and asked if they were willing to participate in a follow-up. The follow-up included an interview and a clinical study. In the clinical study, breed, age, and weight were recorded, as was information on clinical signs of possible prostatic disease. Ultrasonography of the prostate was performed at one of the two animal hospitals and two animal clinics that participated in the original study. A venous blood sample was collected for analysis of CPSE and steroid hormones.

\section{Interview}

Owners were contacted via phone (Additional file 1). Questions included if the dog was still alive, and if it was or had been treated for prostatic problems. The owners were also asked if the dog had been surgically castrated or if it was treated with deslorelin. If the dog was not 
alive, the owner was questioned about the reason for euthanasia.

\section{Inclusion and exclusion criteria for clinical part}

Inclusion criteria were male dogs that had been included in the previous study (baseline) [4]. Exclusion criteria were treatment for prostatic disease or castrated since baseline (3 years earlier).

\section{Ultrasonography}

The prostate was examined using the previously described standardized protocol [4] by experienced veterinary surgeons that had adequate equipment ${ }^{1}$. Transducer type and frequency were optimized for the individual dog to cover the entire prostate for measurements and to get as good detail resolution as possible for the parenchymal evaluation.

Length, width, and height of the prostate were measured three times on different still images and the mean values were used in further calculations. The prostatic volume $(\mathrm{V})$ for the individual dog was calculated according to Kamolpatana et al. as $\mathrm{V}=(1 / 2.6)$ * (Length * Width * Height) $+1.8 \mathrm{~cm}^{3}$ [16]. In addition prostatic parenchyma (homogenous or heterogenous), contour (smooth or uneven); shape (symmetrical or asymmetrical), and presence of cysts (none, 1-5 or $>5$ ) were recorded.

\section{Analysis of CPSE}

Venous blood samples were collected and serum was stored at $-70{ }^{\circ} \mathrm{C}$ until CPSE was analyzed using a commercial ELISA; Odelis ${ }^{\circ}$ CPSE (Virbac). Intra assay coefficient of variation $(\mathrm{CV})$ was $<5 \%$ and interassay $\mathrm{CV}$ was $<7 \%$, according to the manufacturer. Samples with concentrations $\geq 200 \mathrm{ng} / \mathrm{mL}$ were diluted $1: 10$ and reanalyzed.

\section{Analysis of steroid hormones}

An analysis of steroid hormones was performed by supercritical fluid chromatography-tandem mass spectrometry (SFC-MS/MS, Waters Corporation, Milford, MA, USA) system [37]. A slightly modified method of liquid -liquid extraction was used [37]. In brief, a $50 \mu \mathrm{L}$ of plasma was spiked with $50 \mu \mathrm{L}$ mixture of a corresponding deuterated internal standard mixture $(10 \mu \mathrm{g} / \mathrm{mL})$. The protein precipitation was achieved by the addition of $100 \mu \mathrm{L}$ of ice cooled $\mathrm{MeOH}$ and followed by the addition of $200 \mu \mathrm{L}$ of MTBE, then vortexed for $15 \mathrm{~min}$. Samples were centrifuged at $13,000 \mathrm{rpm}$ for $10 \mathrm{~min}$ at $4{ }^{\circ} \mathrm{C}$. The supernatant was transferred to a clean tube

${ }^{1}$ GE Medical LOGIQ 9 Ultrasound Imaging System, General Electric Medical Systems, MyLab ${ }^{\text {Tw }}$ Alpha, Esaote SpA, Philips IE33 Ultrasound, Philips Medical Systems and evaporated under a stream of nitrogen and the steroids were derivatized in to their methoximes prior to analysis [37]. The SFC system was equipped with a Acquity $\mathrm{UPC}^{2} \mathrm{BEH}$ column $(150 \mathrm{~mm} \times 3.0 \mathrm{~mm}, 1.7 \mu \mathrm{m}$ particle size; Waters, Milford, MA, USA). It was kept at $40{ }^{\circ} \mathrm{C}$ and at a mobile phase flow rate of $2 \mathrm{~mL} / \mathrm{min}$. The gradient program was started with $98 \%$ A $\left(\mathrm{CO}_{2}\right.$, 99.999\%) and 2\% B (0.1\% formic acid in methanol/isopropanol (1:1)), linearly increased to $17 \% \mathrm{~B}$ over $3 \mathrm{~min}$, held at $17 \%$ B for $0.5 \mathrm{~min}$, followed by a linear gradient down to $2 \%$ B over $0.5 \mathrm{~min}$. Finally, it was held for $1 \mathrm{~min}$ at $2 \% \mathrm{~B}$ for the elution of ionic liquids out of the instrument, resulting in a total separation time of $5 \mathrm{~min}$. Mass spectrometric detection was performed using electrospray ionization in the positive ionization mode (ESI+) with a capillary voltage of $2.8 \mathrm{kV}$, cone voltage of $30 \mathrm{~V}$, and source offset of $30 \mathrm{~V}$. Nitrogen and argon $(0.15 \mathrm{~mL} /$ min) served as the desolvation gas and the collision gas, respectively. Desolvation temperature was maintained at $500{ }^{\circ} \mathrm{C}$. The quantification of the analytes was based on a multiple reaction monitoring (MRM) coupled to stable isotope dilution. The limit of quantification (LOQ) and co-efficient of variation of steroids were $0.1-0.5 \mathrm{ng} / \mathrm{mL}$ and $8-10 \%$, respectively. The recovery of steroids was more than $85 \%$. Linear rage of the quantification for steroids was $0.1-1000 \mathrm{ng} / \mathrm{mL}$. All data was acquired, analysed and processed using the Waters MassLynx software (version 4.1, Waters, Milford, MA, USA).

\section{Statistical analysis}

The normal prostatic volume $\left(\mathrm{V}_{\text {norm }}\right)$ was calculated according to Sannamwong and coworkers [38]. The formula includes weight of the dogs, and is based on healthy dogs aged $1.5-4$ years: $\mathrm{V}_{\text {norm }}=0.33 * \mathrm{BW}(\mathrm{kg})+$ 3.28. The calculated volume $(\mathrm{V})$ was compared to $\mathrm{V}_{\text {norm }}$ to get a relative value of the prostatic size: $S_{\text {rel }}=V / V_{\text {norm }}$, as previously described [4]. Dogs with a $S_{\text {rel }}>1$ thus had a larger prostate than would be normal for dogs 4 years or younger. $S_{\text {rel }} \geq 2.5$ was considered a clinically relevant enlargement [4].

At baseline, the coefficient of variations (CVs) of the volume of the prostate within a dog, when measured by ultrasonography, was < 15\% [4]. Based on this, volumes smaller or greater than $15 \%$ compared to measurements at baseline were defined as decreases or increases, respectively, and values in between were categorized as no significant change in volume.

A multiple regression analysis was applied to evaluate the effect of CPSE concentrations at baseline and at follow-up on $S_{\text {rel }}$ at follow-up and on the difference between $S_{\text {rel }}$ at baseline and at follow-up. Pearson correlation was used to evaluate the correlation between the CPSE concentration at baseline and $S_{\text {rel }}$ at follow-up. Multiple regression analysis was also used to evaluate 
the effect of steroid concentrations at follow-up on $S_{\text {rel }}$ at follow-up and on the difference between $S_{\text {rel }}$ at baseline and at follow-up. In addition, two separate models were built, one including the steroids as the classes androgens, estrogens, progestins and corticosteroids, and the other including the ratios between the steroid classes. For the multiple regression analyses the residuals were checked and found to be normally distributed, and the use of multiple regression thus deemed appropriate.

Concentrations of CPSE at baseline and follow-up, as well as volume and relative size of the prostate, were mostly not normally distributed (evaluated using the Ryan-Joiner test), and values are therefore presented as median and interquartile range, IQR. Minitab (Minitab 18, Minitab Inc., State College, PA, USA) was used for comparing $\mathrm{V}$ and $\mathrm{S}_{\text {rel }}$ between baseline and follow-up, after numbers had been log-transformed, using the paired t-test. For comparison between groups with increased or similar prostate size between baseline and follow-up, the Kruskal-Wallis test was used. Fisher's exact test was used to compare development of clinical signs depending on CPSE concentration or $\mathrm{S}_{\text {rel }}$ at baseline. McNemar's test was used to compare the numbers of dogs with cysts at baseline and at follow-up. For the multiple regressions, $\mathrm{R}$ [39] was employed.

\section{Abbreviations}

BEH: Ethylene-bridged hybrid; BPH: Benign prostatic hyperplasia; CPSE: Canine prostate specific esterase; CV: Coefficient of variation: ER: Estrogen receptor; IQR: Interquartile range; $\mathrm{MeOH}$ : Methanol; MTBE: Methyl-tert-butyl ether; MRM: Multiple reaction monitoring; PSA: Prostate specific antigen; $S_{\text {rel: }}$ Relative prostatic size; SFC-MS/ MS: Supercritical fluid chromatography - tandem mass spectrometry; V: Calculated prostatic volume; $V_{\text {norm: }}$ : Normal prostatic volume

\section{Supplementary Information}

The online version contains supplementary material available at https://doi. org/10.1186/s12917-021-02874-1.

Additional file 1. Follow-up contact (via phone) with owners of dogs included in a previous study. The file contains questions put forward to dog owners during an interview by telephone.

\section{Acknowledgements}

The authors acknowledge skilled technical assistance from PhD Anna Svensson.

\footnotetext{
Authors' contributions

BSH: Conceptualization, Formal analysis, Funding acquisition, Investigation, Methodology, Project administration, Supervision, Validation, Visualization, Writing - original draft, review \& editing, SC: Investigation, Writing - review \& editing VF-L: Investigation, Resources, Writing - review \& editing SH: Investigation, Resources, Writing - review \& editing; SÖ: Investigation, Resources LML: Investigation, Resources SJKAU: Funding acquisition, Investigation, Resources, Writing - review \& editing JB: Funding acquisition, Resources, Supervision, Writing - review \& editing JR: Formal analysis, Resources, Software, Writing - - review \& editing EH: Investigation KH: Conceptualization, Resources, Supervision, Writing - review \& editing. All authors read and approved the final manuscript.
}

\section{Funding}

This work was supported by Ingeborg Ögrens fund, SLU, Sweden, by the Mass Spectrometry Based Metabolomics Facility at Uppsala University (Chemistry - BMC) in Uppsala, Sweden, and by the Department of Clinical Sciences, Swedish University of Agricultural Sciences, Uppsala, Sweden. Virbac kindly supported the study with Odelis CPSE'M ELISA kits. The funding bodies did not have any role in the design, analysis or reporting of the study. Open Access funding provided by Swedish University of Agricultural Sciences.

\section{Availability of data and materials}

The datasets used and/or analysed during the current study are available from the corresponding author on reasonable request.

\section{Declarations}

\section{Ethics approval and consent to participate}

The study was approved by the Uppsala animal ethical committee, permit number C89/14. Participating dog owners gave their informed written consent.

\section{Consent for publication}

Not applicable.

\section{Competing interests}

The authors declare that they have no competing interests.

\section{Author details}

${ }^{1}$ Department of Clinical Sciences, Swedish University of Agricultural Sciences, Box 7054, SE-750 07 Uppsala, Sweden. ${ }^{2}$ Diagnostic Imaging Clinic, University Animal Hospital, Swedish University of Agricultural Sciences, Uppsala, Sweden. ${ }^{3}$ Evidensia Specialist Animal Hospital Strömsholm, Strömsholm, Sweden. ${ }^{4}$ ReDog Veterinary Clinic, Västerås, Sweden. ${ }^{5}$ Department of Chemistry - Biomedical Center, Analytical Chemistry, Uppsala University, Uppsala, Sweden. ${ }^{6}$ Department of Energy and Technology, Applied Statistics and Mathematics, Swedish University of Agricultural Sciences, Uppsala, Sweden.

Received: 4 November 2020 Accepted: 6 April 2021

Published online: 26 April 2021

\section{References}

1. Berry SJ, Strandberg JD, Saunders WJ, Coffey DS. Development of canine benign prostatic hyperplasia with age. Prostate. 1986;9(4):363-73. https:// doi.org/10.1002/pros.2990090406.

2. Berry SJ, Coffey DS, Ewing LL. Effects of aging on prostate growth in beagles. Am J Phys. 1986;250(6 Pt 2):R1039-46.

3. Brendler CB, Berry SJ, Ewing LL, McCullough AR, Cochran RC, Strandberg JD, et al. Spontaneous benign prostatic hyperplasia in the beagle. Ageassociated changes in serum hormone levels, and the morphology and secretory function of the canine prostate. J Clin Invest. 1983;71(5):1114-23. https://doi.org/10.1172/JCl110861.

4. Holst BS, Holmroos E, Friling L, Hanas S, Langborg LM, Franko MA, et al. The association between the serum concentration of canine prostate specific esterase (CPSE) and the size of the canine prostate. Theriogenology. 2017; 93:33-9. https://doi.org/10.1016/j.theriogenology.2017.01.032.

5. O'Shea JD. Studies on the canine prostate gland. I. Factors influencing its size and weight. J Comp Pathol. 1962;72:321-31. https://doi.org/10.1016/S03 68-1742(62)80037-X.

6. Kawakami E, Amemiya E, Namikawa K, Kashiwagi C, Hori T, Tsutsui T. High plasma estradiol-17beta levels in dogs with benign prostatic hyperplasia and azoospermia. J Vet Med Sci. 2001;63(4):407-12. https://doi.org/10.1292/ jvms.63.407.

7. Wolf K, Kayacelebi H, Urhausen C, Piechotta M, Mischke R, Kramer S, et al. Testicular steroids, prolactin, relaxin and prostate gland markers in peripheral blood and seminal plasma of normal dogs and dogs with prostatic hyperplasia. Reprod Domest Anim. 2012;47(Suppl 6):243-6. https:// doi.org/10.1111/rda.12083.

8. Gangkak G, Bhattar R, Mittal A, Yadav SS, Tomar V, Yadav A, et al. Immunohistochemical analysis of estrogen receptors in prostate and clinical 
correlation in men with benign prostatic hyperplasia. Investig Clin Urol. 2017;58(2):117-26. https://doi.org/10.4111/icu.2017.58.2.117.

9. La Vignera S, Condorelli RA, Russo Gl, Morgia G, Calogero AE. Endocrine control of benign prostatic hyperplasia. Andrology. 2016;4(3):404-11. https:// doi.org/10.1111/andr.12186.

10. Barsanti JA, Finco DR. Canine prostatic diseases. Vet Clin N Am Small Anim Pract. 1986;16(3):587-99. https://doi.org/10.1016/S0195-5616(86)50063-2.

11. Kutzler MA, Yeager A. Prostatic diseases. In: Ettinger SJ, Feldman EC, editors. Textbook of veterinary internal medicine. St. Louis: WB Saunders; 2005. p. 1809-19.

12. Johnston SD, Kamolpatana K, Root-Kustritz MV, Johnston GR. Prostati Disorders in the dog. Animal Reprod Sci. 2000;60-61:405-15.

13. Aquino-Cortez A, Pinheiro BQ, Silva H, Lima D, Silva T, Souza MB, et al. Serum testosterone, sperm quality, cytological, physicochemical and biochemical characteristics of the prostatic fraction of dogs with prostatomegaly. Reprod Domest Anim. 2017;52(6):998-1003. https://doi.org/10.1111/rda.13009.

14. Leví X, Mimouni P. Hyperplasie Bénigne de la Prostate: actualités. Le Point Vétérinaire. 2009;293(3):39-43.

15. Cooney JC, Cartee RE, Gray BW, Rumph PF. Ultrasonography of the canine prostate with histologic correlation. Theriogenology. 1992;38(5):877-95. https://doi.org/10.1016/0093-691X(92)90163-L.

16. Kamolpatana $\mathrm{K}$, Johnston GR, Johnston SD. Determination of canine prostatic volume using transabdominal ultrasonography. Vet Radiol Ultrasound. 2000; 41(1):73-7. https://doi.org/10.1111/j.1740-8261.2000.tb00430.x.

17. Ruel Y, Barthez PY, Mailles A, Begon D. Ultrasonographic evaluation of the prostate in healthy intact dogs. Vet Radiol Ultrasound. 1998;39(3):212-6. https://doi.org/10.1111/j.1740-8261.1998.tb00342.x.

18. Chapdelaine P, Dube JY, Frenette G, Tremblay RR. Identification of arginine esterase as the major androgen-dependent protein secreted by dog prostate and preliminary molecular characterization in seminal plasma. J Androl. 1984;5(3):206-10. https://doi.org/10.1002/j.1939-4640.1984.tb02395.x.

19. Bell FW, Klausner JS, Hayden DW, Lund EM, Liebenstein BB, Feeney DA, et al. Evaluation of serum and seminal plasma markers in the diagnosis of canine prostatic disorders. J Vet Intern Med. 1995;9(3):149-53. https://doi. org/10.1111/j.1939-1676.1995.tb03288.x.

20. Pinheiro D, Machado J, Viegas C, Baptista C, Bastos E, Magalhaes J, et al. Evaluation of biomarker canine-prostate specific arginine esterase (CPSE) for the diagnosis of benign prostatic hyperplasia. BMC Vet Res. 2017;13(1):76. https://doi.org/10.1186/s12917-017-0996-5.

21. Levy X, Nizanski W, von Heimendahl A, Mimouni P. Diagnosis of common prostatic conditions in dogs: an update. Reprod Domest Anim. 2014; 49(Suppl 2):50-7. https://doi.org/10.1111/rda.12296.

22. Alonge S, Melandri M, Leoci R, Lacalandra GM, Aiudi G. Canine prostate specific esterase (CPSE) as an useful biomarker in preventive screening programme of canine prostate: CPSE threshold value assessment and its correlation with ultrasonographic prostatic abnormalities in asymptomatic dogs. Reprod Domest Anim. 2018;53(2):359-64. https://doi.org/10.1111/ rda.13113.

23. Dube JY, Lazure C, Tremblay RR. Dog prostate arginine esterase is related to human prostate specific antigen. Clin Invest Med. 1986;9(1):51-4.

24. Roehrborn CG, McConnell J, Bonilla J, Rosenblatt S, Hudson PB, Malek GH, et al. Serum prostate specific antigen is a strong predictor of future prostate growth in men with benign prostatic hyperplasia. PROSCAR long-term efficacy and safety study. J Urol. 2000;163(1):13-20. https://doi.org/10.1016/ S0022-5347(05)67962-1.

25. Alonge $\mathrm{S}$, Melandri M, Leoci R, Lacalandra GM, Caira M, Aiudi GG. Ejaculation Effect on Canine Prostatic Specific Esterase Serum Concentration. Animals. 2020;10(3):381.

26. Polisca A, Troisi A, Fontaine E, Menchetti L, Fontbonne A. A retrospective study of canine prostatic diseases from 2002 to 2009 at the Alfort veterinary college in France. Theriogenology. 2016;85(5):835-40. https://doi.org/10.101 6/j.theriogenology.2015.10.030.

27. Cozzi B, Ballarin C, Mantovani R, Rota A. Aging and Veterinary Care of Cats, Dogs, and Horses through the Records of Three University Veterinary Hospitals. Front Vet Sci. 2017;4:14

28. Mantziaras G, Alonge S, Faustini M, Luvoni GC. Assessment of the age for a preventive ultrasonographic examination of the prostate in the dog. Theriogenology. 2017;100:114-9. https://doi.org/10.1016/.jtheriogenology.2 017.06.010.

29. Barry MJ, Cockett AT, Holtgrewe HL, McConnell JD, Sihelnik SA, Winfield $\mathrm{HN}$. Relationship of symptoms of prostatism to commonly used physiological and anatomical measures of the severity of benign prostatic hyperplasia. J Urol. 1993;150(2 Pt 1):351-8. https://doi.org/10.1 016/50022-5347(17)35482-4.

30. Ma J, Gharaee-Kermani M, Kunju L, Hollingsworth JM, Adler J, Arruda EM, et al. Prostatic fibrosis is associated with lower urinary tract symptoms. J Urol. 2012;188(4):1375-81. https://doi.org/10.1016/j.juro.2012.06.007.

31. Ruetten H, Wegner KA, Romero MF, Wood MW, Marker PC, Strand D, et al. Prostatic collagen architecture in neutered and intact canines. Prostate. 2018;78(11):839-48. https://doi.org/10.1002/pros.23641.

32. Aaron L, Franco OE, Hayward SW. Review of prostate anatomy and embryology and the etiology of benign prostatic hyperplasia. Urol Clin North Am. 2016;43(3):279-88. https://doi.org/10.1016/.ucl.2016.04.012.

33. Chughtai B, Forde JC, Thomas DD, Laor L, Hossack T, Woo HH, et al. Benign prostatic hyperplasia. Nat Rev Dis Primers. 2016;2(1):16031. https://doi.org/1 $0.1038 /$ nrdp.2016.31

34. Leav I, Schelling KH, Adams JY, Merk FB, Alroy J. Role of canine basal cells in postnatal prostatic development, induction of hyperplasia, and sex hormone-stimulated growth; and the ductal origin of carcinoma. Prostate. 2001;48(3):210-24. https://doi.org/10.1002/pros.1100.

35. Albini A, Bruno A, Bassani B, D'Ambrosio G, Pelosi G, Consonni P, et al. Serum steroid ratio profiles in prostate cancer: a new diagnostic tool toward a personalized medicine approach. Front Endocrinol. 2018;9:110.

36. Bonnett BN, Egenvall A, Hedhammar A, Olson P. Mortality in over 350,000 insured Swedish dogs from 1995-2000: I. breed-, gender-, age- and causespecific rates. Acta Vet Scand. 2005;46(3):105-20. https://doi.org/10.1186/1 751-0147-46-105.

37. de Kock N, Acharya SR, Ubhayasekera S, Bergquist J. A novel targeted analysis of peripheral steroids by ultra-performance supercritical fluid chromatography hyphenated to tandem mass spectrometry. Sci Rep. 2018; 8(1):16993. https://doi.org/10.1038/s41598-018-35007-0.

38. Sannamwong N, Saengklub N, Sriphuttathachot P, Ponglowhapan S. Formula-derived prostate volume determination of normal healthy intact dogs in comparison to dogs with clinical BPH. In: 7th International Symposium on Canine and Feline Reproduction. Whistler: 2012. p. 226.

39. R Core Team. R: A language and environment for statistical computing. Vienna: R Foundation for Statistical Computing; 2019.

\section{Publisher's Note}

Springer Nature remains neutral with regard to jurisdictional claims in published maps and institutional affiliations.
Ready to submit your research? Choose BMC and benefit from:
- fast, convenient online submission
- thorough peer review by experienced researchers in your field
- rapid publication on acceptance
- support for research data, including large and complex data types
- gold Open Access which fosters wider collaboration and increased citations
- maximum visibility for your research: over $100 \mathrm{M}$ website views per year
At BMC, research is always in progress. 